Cahiers d'études africaines

184|2006

Parentés, plaisanteries et politique

\title{
Jolly, Éric. - Boire avec esprit. Bière de mil et société
} dogon

Nanterre, Société d'Ethnologie, 2004, 499 p.

\section{Anne Doquet}

\section{OpenEdition}

\section{Journals}

Édition électronique

URL : http://journals.openedition.org/etudesafricaines/6271

DOI : 10.4000/etudesafricaines.6271

ISSN : $1777-5353$

Éditeur

Éditions de l'EHESS

Édition imprimée

Date de publication : 1 décembre 2006

ISBN : 978-2-7132-2129-3

ISSN : 0008-0055

Référence électronique

Anne Doquet, "Jolly, Éric. - Boire avec esprit. Bière de mil et société dogon », Cahiers d'études africaines [En ligne], 184 | 2006, mis en ligne le 08 décembre 2006, consulté le 23 septembre 2020. URL : http:// journals.openedition.org/etudesafricaines/6271; DOI : https://doi.org/10.4000/etudesafricaines.6271

Ce document a été généré automatiquement le 23 septembre 2020

(c) Cahiers d'Études africaines 


\section{Jolly, Éric. - Boire avec esprit. Bière de mil et société dogon}

Nanterre, Société d'Ethnologie, 2004, 499 p.

\section{Anne Doquet}

1 Systématiquement citée dans les travaux de la dernière décennie consacrés aux Dogon, la recherche d'Éric Jolly sur la bière de mil voit enfin le jour, dans une version de sa thèse remaniée et enrichie d'une importante réflexion sur l'individu dogon. La publication de Boire avec esprit devrait ainsi réjouir plus d'un chercheur, quelle que soit son école. Ne s'inscrivant ni dans la continuité de l'équipe griaulienne qui a focalisé toute son attention sur la cosmogonie, ni du côté des pourfendeurs de ce pilier de l'ethnologie africaniste française, Éric Jolly détient une place spécifique au sein de l'anthropologie de cette société sur-ethnologisée. Son originalité découle en premier lieu de l'option qu'il prit dès le début de ses travaux d'enquêter dans une zone différente de celles de la plupart de ses compatriotes (si l'on excepte les travaux de J. Bouju ou ceux, plus récents, de G. Holder). Mais c'est sans doute la minutie de son travail ethnographique qui a valu à l'auteur le succès de sa thèse trop longtemps non publiée. Combinant une réelle expérience du terrain dogon sur la longue durée à une maîtrise de la langue que beaucoup peuvent lui envier, l'auteur est venu combler une lacune fondamentale de la littérature sur les Dogon: le manque de données ethnographiques, qui remontait quasiment aux années 1940. L'ouvrage de Denise Paulme, Organisation sociale des Dogon (1940), constitue en effet la base de données majeure des travaux contemporains. C'est un des mérites essentiels de Boire avec esprit que de renouveler ces données aujourd'hui.

2 Mais au-delà de ses indéniables qualités d'ethnographe, c'est la démarche anthropologique de l'auteur qui fait la force de son travail. À partir d'un élément concret, la bière de mil, l'ouvrage nous promène dans les sphères contemporaines de la vie sociale, économique, religieuse et politique des Dogon, édifiant au passage une somme de données inédites sur la société.

3 Si la lecture de la "présentation générale » de la société élaborée en première partie peut laisser craindre un modèle monographique à tiroirs, le reste de l'ouvrage montre 
qu'il n'en est rien. Émaillé de nombreux extraits tirés tantôt de la tradition orale, tantôt d'entretiens, le texte déjoue les pièges de l'extrapolation par un recours permanent aux faits et aux paroles vécues. Dans le même temps, il parvient à dessiner l'évolution de la société en explorant les multiples dimensions de la bière - définie comme «fait social transversal »- et par là même, les recoins de la vie quotidienne. Tout en montrant comment la bière crée de la continuité en inscrivant l'homme, le mil, les rituels et les villages dans un système circulaire, l'auteur décrit une pluralité de manières de boire, qui sont autant de stratégies sociales, religieuses ou politiques. La variation des modes de consommation éclaire par exemple les évolutions du christianisme et de l'islam, religions au mieux évoquées sinon ignorées dans les textes concernant les Dogon. L'étude du rapport à la boisson traverse aussi les hiérarchies sociales, et l'on découvre aussi bien les stratégies des plus jeunes, avec l'introduction de nouveaux modes d'alcoolisation, que les initiatives féminines masquées derrière la fabrication et la consommation. É. Jolly nous convie ainsi à un va-et-vient constant entre pratiques collectives et expériences personnelles, les multiples anecdotes relatées éclairant toutes sortes de bricolages identitaires dont d'importants processus de singularisation. Bref, on a ici affaire à des sujets dogons, dont les expressions verbales et comportementales sont pour une fois analysées dans le contexte social et non plus dans un cadre mythique sur-interprété. Mais s'il refuse d'emblée de s'inscrire dans ce cadre analytique classique, l'auteur ne fait pas pour autant fi de la littérature orale, dans laquelle il puise de nombreux textes en lien avec les réalités concrètement observées. L'option qu'il choisit d'éclairer l'organisation sociale par la littérature orale constitue une exception dans les écrits consacrés aux Dogon qui ont systématiquement utilisé les représentations comme sources d'explications de réalités jamais observées. Sans rejeter en bloc les écrits antérieurs qu'il cite abondamment pour en confirmer ou en infirmer la validité selon les cas, Éric Jolly a choisi un angle d'appréhension qui lui permet à la fois d'exploiter la littérature ethnologique et de s'en démarquer.

De même, l'auteur est parvenu à contourner les pièges d'un fonctionnalisme abusif, en ne cherchant nullement à circonscrire "le" rôle de la bière dans la société, mais préférant en suivre les cheminements, même les plus sinueux. Et c'est au long de ce parcours qu'il met à mal quelques clichés devenus, faute de terrain, des évidences anthropologiques décalées d'avec la réalité. L'opposition binaire aînés/cadets prend par exemple ici une forme triangulaire, tout comme l'assimilation du surplus céréalier au gaspillage perd son sens. En démontant ces évidences, les pistes de recherche ouvertes ici (notamment les processus d'individualisation en contexte villageois, domaine que les anthropologues réservent habituellement à la ville) dépassent le cadre dogon pour s'étendre à des problématiques africanistes contemporaines. On peut juste déplorer dans cet ouvrage une tendance à minimiser, sinon à ignorer, les enjeux du tourisme et de la patrimonialisation dans un village situé entre les deux zones les plus touristiques de la région et au cœur de la zone classée de l'Unesco. Il serait en effet étonnant que les habitants de Konsogu ne se sentent nullement concernés, ou n'activent aucune stratégie pour s'emparer de ces phénomènes.

Reste qu'après un trop long voyage dans l'univers des mythes, les Dogon de l'ethnologie remettent enfin les pieds sur terre, dans une société où les marques de l'individualité sont possibles. L'extrême mythification de la culture dogon fut certes remise en question ces dernières années, mais les données relatives à l'organisation sociale faisaient toujours largement défaut. Il était par conséquent grand temps que l'anthropologie des Dogon bénéficie d'un nouveau support pour sortir du débat pro ou 
anti-griaulien dans lequel elle avait tendance à s'enfermer. Sommes toutes, l'objectif que s'était fixé l'auteur, "restituer la diversité et le dynamisme de la société dogon », nous semble atteint. 